\title{
Angiostrongylus cantonensis infection in molluscs in the municipality of São Gonçalo, a metropolitan area of Rio de Janeiro, Brazil: role of the invasive species Achatina fulica in parasite transmission dynamics
}

\author{
Ana PM Oliveira', Rosana Gentile ${ }^{2 /+}$, Arnaldo Maldonado Júnior², \\ Eduardo J Lopes Torres ${ }^{3}$, Silvana C Thiengo ${ }^{4}$
}

\begin{abstract}
1'Fundação Oswaldo Cruz, Instituto Oswaldo Cruz, Programa de Pós-Graduação em Biologia Parasitária, Rio de Janeiro, RJ, Brasil ${ }^{2}$ Fundação Oswaldo Cruz, Instituto Oswaldo Cruz, Laboratório de Biologia e Parasitologia de Mamíferos Silvestres Reservatórios, Rio de Janeiro, RJ, Brasil ${ }^{3}$ Universidade do Estado do Rio de Janeiro, Faculdade de Ciências Médicas, Departamento de Microbiologia, Imunologia e Parasitologia, Laboratório de Helmintologia Romero Lascasas Porto, Rio de Janeiro, RJ, Brasil ${ }^{4}$ Fundação Oswaldo Cruz, Instituto Oswaldo Cruz, Laboratório de Malacologia, Rio de Janeiro, RJ, Brasil
\end{abstract}

The aim of this study was to analyse the infection dynamics of Angiostrongylus cantonensis in its possible intermediate hosts over two years in an urban area in the state of Rio de Janeiro where the presence of A. cantonensis had been previously recorded in molluscs. Four of the seven mollusc species found in the study were exotic. Bradybaena similaris was the most abundant, followed by Achatina fulica, Streptaxis $s p$., Subulina octona, Bulimulus tenuissimus, Sarasinula linguaeformis and Leptinaria unilamellata. Only A. fulica and B. similaris were parasitised by A. cantonensis and both presented co-infection with other helminths. The prevalence of $\mathrm{A}$. cantonensis in $\mathrm{A}$. fulica was more than 50\% throughout the study. There was an inverse correlation between the population size of A. fulica and the prevalence of $\mathrm{A}$. cantonensis and abundance of the latter was negatively related to rainfall. The overall prevalence of A. cantonensis in B. similaris was $24.6 \%$. A. fulica was the most important intermediary host of A. cantonensis in the studied area and B. similaris was secondary in importance for A. cantonensis transmission dynamics.

Key words: cerebral angiostrongyliasis - Bradybaena similaris - helminths' larvae - intermediate hosts

\begin{abstract}
Angiostrongylus cantonensis (Chen, 1935), the rat lungworm, is a parasitic nematode discovered in the pulmonary arteries and hearts of domestic rats in China (Wang et al. 2008). It cans parasitise the central nervous system of humans causing eosinophilic meningitis. The disease is known as cerebral angiostrongyliasis (Hsu et al. 1990, Ismail \& Arsura 1993) or, commonly, rat lungworm disease (RLD). The first record of angiostrongyliasis caused by $A$. cantonensis infection was reported in 1945, by Nomura and Lin, based on the observation of a nematode in the cerebrospinal fluid of a patient (Prociv \& Carlisle 2000). Since then, RLD, which is endemic in Southeast Asia and the Pacific islands, has been reported in more than 30 countries worldwide, especially in tropical and subtropical regions (Kim et al. 2014). Among 2,800 cases of RLD, 77\% occurred in Southeast Asia, China and Japan (Wang et al. 2008). In Brazil, RLD is an emerging disease first reported in 2006 and infected hosts were observed in the states of Rio de Janeiro (RJ), Espírito Santo (ES), Pernambuco (PE), São Paulo, Rio Grande do Sul and Paraná (Caldeira et al. 2007, Lima et al. 2009, Espírito-Santo et al. 2013, Morassutti et al. 2014).
\end{abstract}

doi: 10.1590/0074-02760150106

Financial support: CNPq, IOC-FIOCRUZ

APMO received grants from CNPq.

+ Corresponding author: rgentile@ioc.fiocruz.br

Received 17 March 2015

Accepted 22 July 2015
The life cycle of $A$. cantonensis is complex and involves rats as definitive hosts, molluscs as intermediate hosts and crustaceans, frogs, fishes and other invertebrates as paratenic hosts. Several gastropod species from various families have been reported as intermediate hosts of $A$. cantonensis (Kim et al. 2014), including Achatina fulica, Browdich, 1822, popularly known as the African giant snail (Mead 1961, Alicata 1966, Tsai et al. 2013, Morassuti et al. 2014). A. fulica was included on a list of 100 of the worst invasive species in the world (Lowe et al. 2004). In Brazil it was introduced for commercial purposes in the 1980s and currently is found in 25 of the 26 Brazilian states (Thiengo et al. 2007), usually forming dense populations. A. fulica and other molluscs naturally infected with A. cantonensis have been described in various regions of Brazil by Thiengo et al. (2010), Maldonado Jr et al. (2010), Carvalho et al. (2012) and Moreira et al. (2013).

In Brazil, the emergence of RLD cases associated with the introduction and spread of A. fulica requires a better understanding of RLD transmission dynamics. The aim of this study was to analyse infection dynamics of $A$. cantonensis in its possible intermediate hosts in an urban area in $\mathrm{RJ}$ where the presence of $A$. cantonensis in molluscs has been recorded.

\section{MATERIALS AND METHODS}

Study area - This study was carried out in Trindade locality (22099'37'S $\left.43^{\circ} 03^{\prime} 14^{\prime \prime} \mathrm{W}\right)$, which is a district of the municipality of São Gonçalo (Fig. 1), the second most populous city in RJ with approximately one million inhabitants (IBGE 2010). The climate is warm humid tropical with hot humid summers and mild dry winters. 


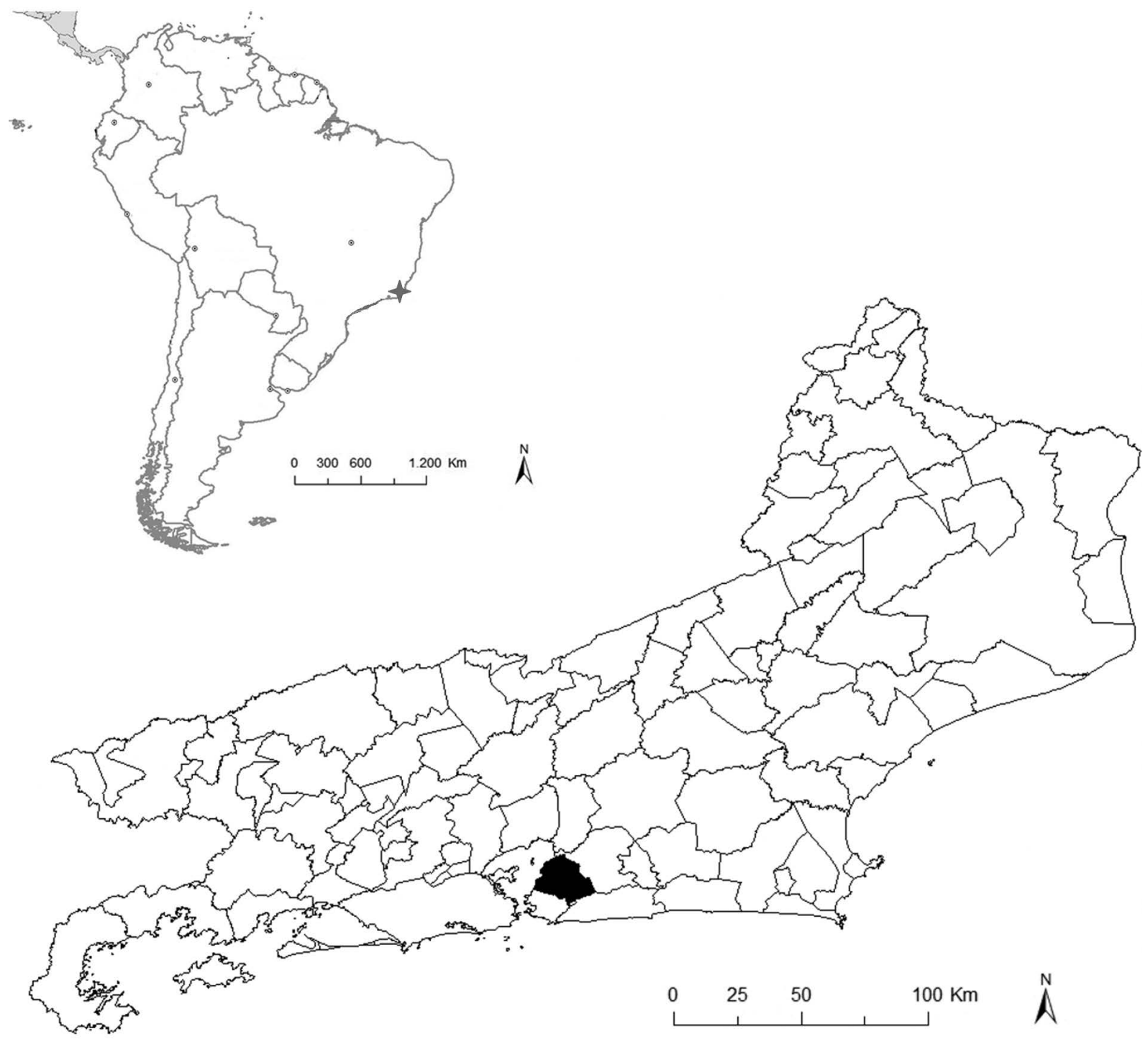

Fig. 1: location of the state of Rio de Janeiro, Brazil, and the municipality of São Gonçalo (black) within the state.

The annual average temperature is $25^{\circ} \mathrm{C}$. Maximum average temperature during the study period was $30.9^{\circ} \mathrm{C}$ in February 2010 and the minimum average temperature was $21^{\circ} \mathrm{C}$ in June 2010 and July 2011. The annual average rainfall is $120 \mathrm{~mm}$ and varied during the study period from $13.9 \mathrm{~mm}$ in September 2011 to $341.2 \mathrm{~mm}$ in March 2010 (data obtained from São Gonçalo Urban Climatological Station from Geosciences Laboratory, Rio de Janeiro State University).

The study site comprised an area of $75 \mathrm{~m}^{2}$ divided into three plots of $5 \times 5 \mathrm{~min}$ grassy vegetation with a predominance of razor grass and a few bushes in the backyards of human dwellings where the presence of $A$. cantonensis had been recorded (Maldonado Jr et al. 2010). The plots were bordered by a pavement way, a dwelling wall, a small stream and a very narrow strip of grass vegetation continuing along the backyards of the dwellings. In two plots, vegetation covered the ground completely and the third plot had open areas with exposured clay soil.
Field and laboratory methods - Molluscs were sampled on 11 occasions in all seasons from January 2010-October 2011. On each occasion, specimens were collected manually on one day, always in the morning. Specimens were taken to the laboratory and kept in a terrarium $(20 \times 19 \times 30 \mathrm{~cm})$ with $3 \mathrm{~cm}$ of autoclaved moist clay on the bottom, under controlled temperature $\left(23 \pm 2^{\circ} \mathrm{C}\right)$ and fed fresh lettuce leaves every other day. Mollusc identification followed Boffi (1979), Araújo et al. (1960) and Thomé and Gomes (2006).

Larvae of helminths were recovered from the molluscs using a $0.7 \% \mathrm{HCl}$ artificial digestion method (Graeff-Teixeira \& Morera 1995). Larvae were fixed in ethanol alcohol $70 \%$, formaldehyde $40 \%$ and acetic acid $\geq$ 99.85\% glacial and identified using a light microscope according to Anderson et al. (2009) and Ash (1970). Larvae recovered from each mollusc specimen were counted only for A. fulica. To confirm identification of A. cantonensis specimens, recovered worms were administered orally 
to rats (Rattus norvergicus) in captivity. After 35 days, adult worms were recovered from the pulmonary arteries of the rats and identified by morphometry according to Maldonado Jr et al. (2010) and by molecular techniques according to Monte et al. (2012). This procedure was carried out following the Ethical Committee on Animal Use of Oswaldo Cruz Foundation (license 100/2011).

Data analysis - Mollusc abundance was defined as the number of specimens of each species collected. Mollusc species richness was defined as the overall number of species sampled.

The prevalence of each helminth species was calculated for each month for all mollusc species and prevalence was defined as the proportion of infected molluscs for a given helminth species in relation to the total number of molluscs analysed for a given mollusc species, according to Bush et al. (2001). To investigate any possible immediate relationship between climatic variables and helminth prevalence, the influence of climatic variables on prevalence of $A$. cantonensis in A. fulica and in Bradybaena similaris (the molluscs species in which A. cantonensis was found) was investigated using multiple linear regressions, with a one-month time lag. To investigate if mollusc abundance and $A$. cantonensis prevalence varied in similar or opposing ways, simple correlations were carried out between these parameters.

Abundance and intensity of $A$. cantonensis in $A$. fulica were calculated for each month according to Bush et al. (2001). Abundance was defined as the number of helminths recovered divided by the total number of molluscs analysed. Intensity was defined as the number of helminths recovered divided by the number of infected molluscs. The dispersion index for A. cantonensis in $A$. fulica was calculated as the variance to mean ratio of parasite abundance. We used simple correlations to investigate whether $A$. fulica abundance and $A$. cantonensis abundance and intensity varied in similar ways through time. To verify possible influence of $A$. fulica shell size on abundance and prevalence of $A$. cantonensis we used simple linear regressions. Shell size was defined as length of the molluse from the apex to the shell opening.

Data on mollusc abundance, parasitological parameters and climatic variables were tested for normal distribution using the Shapiro-Wilk test. Significance level in all analyses was considered as $\alpha<0.05$. Tests were performed using PASW Statistics v.18 and PAST v.2.10.

\section{RESULTS}

Mollusc community - The mollusc community was composed of seven species (overall species richness) and it did not vary among plots. Monthly species richness varied from one-six, with highest values during the winter months. In total, 467 individuals were collected. $B$. similaris was the most abundant species, with 245 individuals, representing $52.4 \%$ of all molluscs collected. A. fulica was the second most abundant (153 individuals, 32.7\%). Other species occasionally present were Streptaxis sp. (22 individuals, $4.7 \%$ ), Subulina octona (11 individuals, 2.3\%), Bulimulus tenuissimus (d'Orbigny, 1835) (9 individuals, 1.9\%), Sarasinula linguaeformis (3 individuals, $0.6 \%$ ) and Leptinaria unilamellata (d'Orbigny, 1835) (2 individuals, 0.4\%).
A. fulica was the only species present in all samples. Its abundance decreased during the study period, except for in April 2011, and it did not exhibit a clear annual pattern of abundance (Fig. 2). B. similaris abundance was highest in September and November 2010 (Fig. 3). There was a negative correlation between $A$. fulica and B. tenuissimus abundances $(r s=-0.619, \mathrm{p}=0.042, \mathrm{n}=11)$.

Helminth parasitism on molluscs - Helminth presence was assessed in 270 mollusc specimens. Three nematode species were found: A. cantonensis, Rhabditis sp. and Strongyluris sp. A. cantonensis had an overall presence of $78.7 \%$ in A. fulica and an overall prevalence of $24.6 \%$ in B. similaris. Rhabditis sp. was present in all mollusc species, except $L$. unilamellata, and had an overall prevalence of $14.2 \%$ in A. fulica, $68.6 \%$ in $B$. similaris, $20 \%$ in S. octona, $31.8 \%$ in B. tenuissimus, $33.3 \%$ in Sarasinula sp. and 9.5\% in Streptaxis sp. Strongyluris sp. occurred only in A. fulica and in B. similaris with overall prevalence of $13.5 \%$ and $2.12 \%$, respectively.

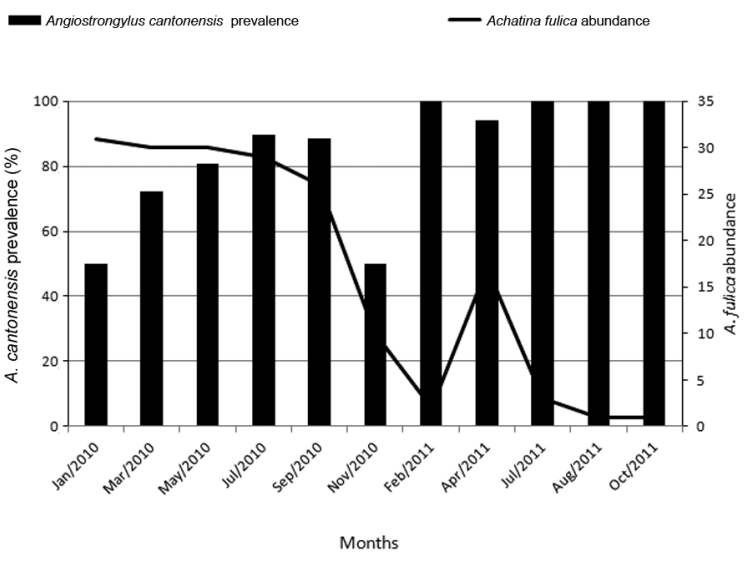

Fig. 2: A. fulica abundance (right axis) and $A$. cantonensis prevalence in this host (left axis) through time in Trindade, municipality of São Gonçalo, state of Rio de Janeiro, Brazil.

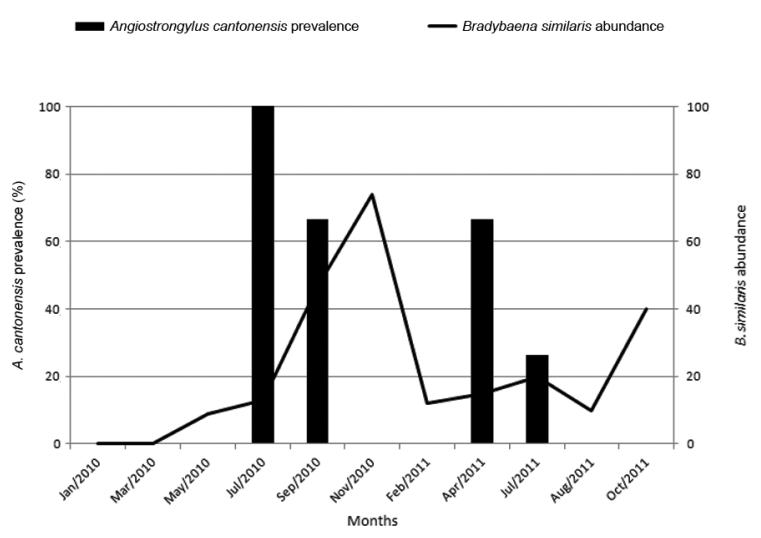

Fig. 3: B. similaris abundance (right axis) and A. cantonensis prevalence in this host (left axis) through time in Trindade, municipality of São Gonçalo, state of Rio de Janeiro, Brazil. 
A. cantonensis infection in molluscs - Prevalence of A. cantonensis on $A$. fulica was always more than $50 \%$ (Fig. 2) and showed a negative correlation with A. fulica abundance $(r s=-0.801, \mathrm{p}=0.003, \mathrm{n}=11)$. Monthly mean abundance of $A$. cantonensis in A. fulica was 124.3 larvae per host varying from 14 in February 2011 to 416.8 in January 2010. Monthly mean intensity of $A$. cantonensis in $A$. fulica was of 220.5 larvae per infected host, varying from 14 in February 2011 to 833.6 in January 2010. A. cantonensis abundance and intensity were not correlated with $A$. fulica abundance ( $r s=0.201, \mathrm{p}=0.535, \mathrm{n}=11 ; r s$ $=0.420, \mathrm{p}=0.198, \mathrm{n}=11$, respectively). However, $A$. cantonensis abundance was related negatively with rainfall $(R$ $=0.788, \mathrm{~b}=-0.951, \mathrm{p}=0.007)$. Prevalence and intensity were not related with any climatic variable. Distribution of $A$. cantonensis was highly aggregated among $A$. fulica individuals with a dispersion index of 952.81 and the highest absolute abundance in one mollusc was 3,108 larvae.

Overall prevalence of $A$. cantonensis in $B$. similaris was $24.6 \%$, varying from $0-100 \%$. This helminth was found in B. similaris only in July 2010, September 2010, April 2011 and July 2011 (Fig. 3). There was no relation between prevalence and any climatic variable $(R=0.369$, $\mathrm{p}=0.294)$. There was no correlation between $A$. cantonensis prevalence and $B$. similaris abundance $(r=0.035$, $\mathrm{p}=0.918, \mathrm{n}=11$ ) nor between $A$. cantonensis prevalence in $A$. fulica and A. cantonensis prevalence in B. similaris $(r=0.276, \mathrm{p}=0.412, \mathrm{n}=11)$. Abundance and intensity in $B$. similaris were not calculated because the snails were pooled for digestion and larvae were not counted.

Shell size of the $A$. fulica specimens collected varied from $1-9 \mathrm{~cm}$, with a mean of $4.35 \mathrm{~cm}$ and a standard deviation of 1.67. There was no significant correlation between $A$. fulica shell size and helminth abundance $(R$ $=0.029, \mathrm{p}=0.727, \mathrm{n}=142)$, nor between monthly median shell size and $A$. cantonensis monthly prevalence $(R=$ $0.499, \mathrm{p}=0.118, \mathrm{n}=10$ ).

\section{DISCUSSION}

Four of the seven mollusc species found in the study are considered exotic (A. fulica, B. similaris, L. unilamellata and $S$. octona) and three are native (B. tenuissimus, S. linguaeformis and Streptaxis sp.) (Simone 2006). These species are widely distributed and some play a role in transmission of helminth parasites of medical and veterinary importance (Souza \& Lima 1990). The invasive species $A$. fulica stands out for its recent introduction and for rapidly spreading throughout Brazil (Thiengo et al. 2007, Zanol et al. 2010), including RJ (Carvalho et al. 2012). In the present study, abundance of $A$. fulica and $B$. similaris were higher than in other studies conducted in A. cantonensis transmission areas in Brazil. Carvalho et al. (2012) studied mollusc fauna in nine Brazilian ports, finding $S$. octona to be most abundant, followed by $A$. fulica and $B$. similaris. The same was found by Caldeira et al. (2007) in ES. Thiengo et al. (2010) reported a predominance of $L$. unilamellata, Sarasinula marginata and $A$. fulica in PE and did not find $B$. similaris.

$A$. fulica and B. similaris, originating in Africa and Asia, respectively, have been introduced to many regions of the world by human activities. In Brazil, they occur in nearly all states (Oliveira et al. 1990, Zanol et al. 2010). They spread easily to various environments and can cause major health and economic effects, either as agricultural pests or as intermediate hosts of helminths. In addition, they are able to establish readily in urban and periurban areas, invading gardens, vegetable gardens and wastelands. These characteristics may have resulted in higher abundance of $A$. fulica and $B$. similaris compared to other mollusc species in the area studied. Exotic invasive species tend to dominate the natural communities where they establish (Simone 2006).

We observed a marked increase in B. similaris abundance in spring and summer. These results are according to Araújo (1989), who found seasonal occurrence of this species with activities after periods of heavy rainfall, restricting its appearance to relatively short periods of the year. Leahy $(1980,1983)$ found high resistance to environmental changes by $B$. similaris and ability to survive to desiccation for up to 24 days and to return to normal activity when replaced in moist environments with food. In general, terrestrial pulmonate molluses tend to be more active in the rainy season, when relative humidity of air and soil are higher (Pérez et al. 2008). Mollusc species richness did not vary among plots, but varied over time, increasing in the winter months, especially due to the accidental species Streptaxis sp., L unilamellata and $S$. linguaeformis moving from adjacent vegetation, which seemed to be dependent on seasonal variations.

The present study is the first report of the occurrence of $A$. cantonensis in B. similaris in RJ, although $B$. similaris has been identified as an intermediate host of this nematode elsewhere (Caldeira et al. 2007, Carvalho et al. 2012). Results of the present study indicate $A$. fulica and $B$. similaris as the most important intermediate hosts of $A$. cantonensis in Trindade, with much higher prevalence in $A$. fulica than in B. similaris. In addition, results indicate an important role of $A$. fulica in the transmission cycle of A. cantonensis, because this species was found infected throughout the year at high prevalence rates. A. fulica seems to be susceptible to various parasite species, which corroborates its importance as a helminth intermediate host. Furthermore, its body size and high abundance may favour parasite occurrence. Larger hosts may offer more space and diversity of microhabitats and they are able to support a greater richness of parasite species.

Prevalence and abundance of $A$. cantonensis increased most during and at the end of the dry season. In November 2010, as A. fulica abundance decreased, the prevalence of $A$. cantonensis dropped. At this point, $B$. similaris abundance was highest and in both 2010 and 2011, the highest prevalence of $A$. cantonensis on this host species occurred during the first months of $A$. fulica abundance decrease. Moreover, even with lower abundance of $A$. fulica in 2011, prevalence of the nematode in this host always was high. These observations suggest $B$. similaris as the second most significant host for the A. cantonensis transmission cycle. Although this mollusc was the most abundant in the present study, A. cantonensis infection was observed only during dry months. Carvalho et al. (2012) showed that, in Brazilian port areas, the rate of infection of $A$. cantonensis in $B$. similaris was 
$100 \%$, in S. marginata, $84 \%$, in S. octona, $76 \%$ and in A. fulica, $66 \%$. They concluded that $B$. similaris had importance equal to or greater than A. fulica in the parasite transmission cycle. In the present study, it is possible that $B$. similaris acted as an auxiliary intermediate host for the parasite transmission. It is important to point out that the present study was carried out over nearly two years, while Carvalho et al. study (2012) was less protracted.

The dispersion of parasites is of great importance to understanding parasite-host dynamics (De Jong 1976, Dobson \& Roberts 1994). We observed a highly aggregated distribution pattern of A. cantonensis in A. fulica population, indicating that unequal exposure of hosts and differences in individual susceptibility to infection may have influenced this pattern and resulted in many hosts harbouring few or no parasites and a few hosts harbouring the bulk of parasites as expected for most parasite populations (Poulin 2007).

Although the highest mean parasite load of $A$. cantonensis in A. fulica was observed in the older age group, we did not observe a significant relationship between $A$. fulica shell size and abundance of $A$. cantonensis, suggesting that helminth larvae infection did not depend on mollusc shell size. Sithithaworn et al. (1991) demonstrated that $A$. cantonensis prevalence may increase with A. fulica age and hosts of up to 200 days reached a $50-60 \%$ infection level, with total prevalence of $53 \%$ at this age and size. Thus, in the present study, the microenvironment may have influenced infection more than shell size, due to high degree of spatial aggregation of parasites in the A. fulica population.

Recent studies have reported $A$. cantonensis infection in Brazil in Rattus rattus and R. norvergicus, with both acting as definitive hosts (Simões et al. 2011, Moreira et al. 2013). In the studied area, infected $R$. norvergicus were observed to have high prevalence and abundance of A. cantonensis and to contribute to dispersing the parasite to new areas (Simões et al. 2014).

In the present study, A. fulica played an important role as intermediate host in the $A$. cantonensis transmission dynamics, due to its high abundance and high infection rates, regardless of season. $B$. similaris was a second most important to A. cantonensis transmission dynamics, mostly when population abundance of $A$. fulica was low. The high abundance of these molluscs observed associated with high prevalence of $A$. cantonensis and the presence of infected rodents may enable transmission of this nematode in the locality throughout the year.

\section{ACKNOWLEDGEMENTS}

To the staff of the Department of Health of São Gonçalo for support during the field work.

\section{REFERENCES}

Alicata JE 1966. The presence of Angiostrongylus cantonensis in the islands of the Indian Ocean and probable role of the Giant African snail, Achatina fulica, in dispersal of the parasite to the Pacific islands. Can J Zool 44: 1041-1049.

Anderson RC, Chabaud AG, Willmott S 2009. Keys to the nematode parasites of vertebrates: archival volume, MPG Books Group, Oxfordshire, $463 \mathrm{pp}$.
Araújo JLB 1989. Moluscos de importância econômica no Brasil. I. Xanthonychidae: Bradybaena similaris (Férussac, 1821) (Mollusca, Gastropoda, Pulmonata, Stylommatophora). Rev Bras Zool 6: 583-592.

Araújo JLB, Rezende HEB, Rodrigues PAF 1960. Sobre "Bulimulus tenuissimus" (Orbigny, 1835) (Gastropoda, Pulmonata). Rev Bras Biol 20: 33-42.

Ash LR 1970. Diagnostic morphology of the third-stage larvae of Angiostrongylus cantonensis, Angiostrongylus vasorum, Angiostrongylus abstrusus and (Nematoda: Metastrongyloidea) Anafilaroides rostratus. J Parasitol 56: 249-253.

Boffi AV 1979. Moluscos brasileiros de interesse médico e econômico, Hucitec, São Paulo, 182 pp.

Bush AO, Fernandez JC, Esch GW, Seed JR 2001. Parasitism: the diversity and ecology of animal parasites, 1st ed., Cambridge University Press, Cambridge, 576 pp.

Caldeira RL, Mendonça CLGF, Goveia CO, Lenzi HL, Graeff-Teixeira C, Lima WS, Mota EM, Pecora IL, de Medeiros AMZ, Carvalho OS 2007. First record of molluscs naturally infected with Angiostrongylus cantonensis (Chen, 1935) (Nematoda: Metastrongylidae) in Brazil. Mem Inst Oswaldo Cruz 102: 887-889.

Carvalho OS, Scholte RGC, de Mendonça CLF, Passos LKJ, Caldeira RL 2012. Angiostrongylus cantonensis (Nematode: Metastrongyloidea) in molluscs from harbour areas in Brazil. Mem Inst Oswaldo Cruz 107: 740-746.

De Jong 1976. A model of competition for food. I. Frequency-dependent viabilities. Am Nat 110: 1013-1027.

Dobson AP, Roberts M 1994. The population dynamics of parasitic helminth communities. Parasitology 109 (Suppl.): 97-108.

Espírito-Santo MCC, Pinto PLS, Mota DJG, Gryschek RCB 2013. Primeiro caso de meningite eosinofílica diagnosticado na cidade de São Paulo, SP, Brasil. Rev Inst Med Trop Sao Paulo 55: 129-132.

Graeff-Teixeira C, Morera P 1995. Método de digestão de moluscos em ácido clorídrico para isolamento de larvas de metastrongilídeo. Biociencias 3: 85-89.

Hsu WY, Chen JY, Chen CT, Chi CS, Han NT 1990. Eosinophilic meningitis caused by Angiostrongylus cantonensis. Pediatr Infect Dis J 9: 443-445.

IBGE - Instituto Brasileiro de Geografia e Estatística 2010. Cidades@. Available from: cod.ibge.gov.br/233YY.

Ismail Y, Arsura EL 1993. Eosinophilic meningitis associated with coccidioidomycosis. West J Med 158: 300-301.

Kim JR, Hayes KA, Yeung NW, Cowie RH 2014. Diverse gastropod hosts of Angiostrongylus cantonensis, the rat lungworm, globally and with a focus on the Hawaiian Islands. PLoS ONE 9: e94969.

Leahy WM 1980. Aspectos adaptativos de Bradybaena similaris Ferussac, 1821 (Mollusca, gastropoda, Pulmonata) submetido ao jejum e dessecação. Bol Fisiol Anim 5: 47-55.

Leahy WM 1983. Comportamento e características anatomofuncionais da reprodução em Bradybaena similaris (molusco pulmonado). Ci Cult 36: 1389-1392.

Lima AR, Mesquita SD, Santos SS, Aquino ER, Rosa LR, Duarte FS, Teixeira AO, Costa ZR, Ferreira ML 2009. Alicata disease: neuroinfestation by Angiostrongylus cantonensis in Recife, Pernambuco, Brazil. Arq Neuropsiquiatr 67: 1093-1096.

Lowe S, Browne M, Boudjelas S 2004. 100 of the world's worst invasive alien species. A selection from the global invasive species database. Available from: issg.org/database. 
Maldonado Jr A, Simões RO, Oliveira APM, Motta EM, Fernandez MA, Pereira ZM, Monteiro SS, Torres EJL, Thiengo SC 2010. First report of Angiostrongylus cantonensis (Nematoda: Metastrongylidae) in Achatina fulica (Mollusca: Gastropoda) from Southeast and South Brazil. Mem Inst Oswaldo Cruz 105: 938-941.

Mead AR 1961. The giant African snail: a problem in economic malacology, University of Chicago Press, Chicago, 257 pp.

Monte TC, Simões RO, Oliveira APM, Novaes CF, Thiengo SC, Silva AJ, Estrela PC, Maldonado Jr A 2012. Phylogenetic relationship of the Brazilian isolates of the rat lungworm Angiostrongylus cantonensis (Nematoda: Metastrongylidae) employing mitochondrial COI gene sequence data. Parasit Vectors 5: 248.

Morassutti AL, Thiengo SC, Fernades M, Sawanyawisuth K, GraeffTeixeira C 2014. Eosinophilic meningitis caused by Angiostrongylus cantonensis: an emergent disease in Brazil. Mem Inst Oswaldo Cruz 109: 399-407.

Moreira EG, Melo FTV, Simões RO, Thiengo SC, Maldonado Jr A, Santos JN 2013. Endemic angiostrongyliasis in the Brazilian Amazon: natural parasitism of Angiostrongylus cantonensis in Rattus rattus and $R$. norvegicus and sympatric giant African land snails, Achatina fulica. Acta Trop 125: 90-97.

Nomura S, Lin PH 1945. First case of human infection with Haemostrongylus ratti Yokogawa. Taiwan No Ikai 3: 589.

Oliveira MP, Bessa ECA, Sá RCS 1990. Catálogo dos moluscos da Universidade Federal de Juiz de Fora, Vol. 1, Editora da Universidade Federal de Juiz de Fora, Juiz de Fora, 158 pp.

Pérez A, Sotelo MM, Arana I, López A 2008. Diversidad de moluscos gasterópodos terrestres en la región del Pacífico de Nicaragua y sus preferencias de hábitat. Rev Biol Trop 56: 317-332.

Poulin R 2007. Are there general laws in parasite ecology? Parasitology 134: 763-776.

Prociv PD, Carlisle SM 2000. Neuro-angiostrongyliasis: unresolved issues. Int J Parasitol 30: 1295-1303.

Simões RO, Maldonado A, Olifiers N, Garcia JS, Bertolino AVFA, Luque JL 2014. A longitudinal study of Angiostrongylus canto- nensis in an urban population of Rattus norvegicus in Brazil: the influences of seasonality and host features on the pattern of infection. Parasit Vectors 7: 100.

Simões RO, Monteiro FA, Sanchez E, Thiengo SC, Garcia JS, CostaNeto SF, Luque JL, Maldonado A 2011. Endemic angiostrongyliasis in Rio de Janeiro, Brazil. Emerg Infect Dis 17: 1331-1333.

Simone LRL 2006. Land and freshwater molluscs of Brazil, EGB/ Fapesp, São Paulo, 390 pp.

Sithithaworn P, Brockelman WY, Brockelman C 1991. Transmission of Angiostrongylus cantonensis through the giant African snail Achatina fulica: an experimental study. Southeast Asian J Trop Med Public Health 22 (Suppl.): 200-205.

Souza CP, Lima LC 1990. Moluscos de interesse parasitológico do Brasil, Série Esquistossomose 1, Centro de Pesquisa René Rachou-Fiocruz, Belo Horizonte, 76 pp.

Thiengo SC, Faraco FA, Salgado NC, Cowie RH, Fernandez MA 2007. Rapid spread of an invasive snail in South America: the giant African snail, Achatina fulica, in Brasil. Biol Invasions 9: 693-702.

Thiengo SC, Maldonado A, Mota EM, Torres EJL, Caldeira R, Carvalho OS, Oliveira APM, Simões RO, Fernandez MA, Lanfredi RM 2010. The giant African snail Achatina fulica as natural intermediate host of Angiostrongylus cantonensis in Pernambuco, Northeast Brazil. Acta Trop 115: 194-199.

Thomé JW, Gomes SR 2006. Guia ilustrado: os caracóis e as lesmas dos nossos bosques e jardins, União Sul-Americana de Estudos da Biodiversidade, Pelotas, 124 pp.

Tsai HC, Chen YS, Yen CM 2013. Human parasitic meningitis caused by Angiostrongylus cantonensis infection in Taiwan. Hawaii J Med Public Health 72: 26-27.

Wang QP, Lai DH, Zhu XQ, Chen XG, Lun ZR 2008. Human angiostrongyliasis. Lancet Infect Dis 8: 621-630.

Zanol J, Fernandez MA, Oliveira APM, Russo CAM, Thiengo SC 2010. O caramujo exótico invasor Achatina fulica (Stylommatophora, Mollusca) no Estado do Rio de Janeiro (Brasil): situação atual. Biota Neotrop 10: 447-451. 